\title{
Title
}

\section{Faculty-Library Collaborations in Digital History: A Case Study of the Travel Journal of Cornelius B. Gold}

\author{
Abbreviated Title \\ Faculty-Library Collaborations in Digital History
}

\author{
Authors \\ University, Columbus, Ohio \\ Connecticut \\ College, New London, Connecticut

\section{Corresponding Author} \\ Ann Marie Davis \\ Assistant Professor and Japanese Studies Librarian \\ The Ohio State University \\ 350B Thompson Library \\ 1858 Neil Ave, Columbus, OH 43210 \\ Phone: 614-292-3502 \\ Email: davis.5257@osu.edu
}

Ann Marie Davis, Assistant Professor and Japanese Studies Librarian, The Ohio State

Jessica McCullough, Instructional Design Librarian, Connecticut College, New London,

Ben Panciera, Ruth Rusch Sheppe '40 Director of Special Collections and Archives, Connecticut

Rebecca Parmer, College Archivist, Connecticut College, New London, Connecticut 


\title{
Faculty-Library Collaborations in Digital History: A Case Study of the Travel Journal of Cornelius B. Gold
}

\begin{abstract}
In this article, the authors present a case study on a teaching and learning initiative in digital humanities at Connecticut College. The article outlines a project in which students in a mid-level history course collaborated with library staff and faculty to develop a digital exhibition on a nineteenth-century journal in the College's collection. The cooperative approach and institutional support that the team received provided an effective and flexible means for achieving common goals. As students applied emergent technologies to college collections, they were able to conduct meaningful research and bring archival resources to new audiences.
\end{abstract}

Keywords: collaboration, digital humanities, student research, special collections, teaching and learning, instructional design

\section{Introduction}

New developments in the digital humanities, information literacy, and instructional design have inspired innovation and collaboration between educators and librarians in growing numbers.

Online exhibits and web sites are a common product of such collaborations, providing meaningful research opportunities to undergraduate students through project-based assignments and independent research opportunities. Advancing course- and discipline-specific goals, project-based digital exhibits can impart critical lessons about research and knowledge production while promoting access to collections in local libraries and archives.

The ensuing article explores the recent application of digital tools to archival sources at a small liberal arts institution, Connecticut College, to extend knowledge and foster new interpretations about the human past. Specifically, the authors discuss a collaborative approach to teaching and technology that showcases the type of "community," or "network," of shared 
interests and values that historian and digital media expert Tom Scheinfeldt theorizes as fundamental to the digital humanities (Scheinfeldt 2010). At Connecticut College, institutional support for innovative teaching allowed the collaborative team to combine forces, harness new technologies, and improve student learning. In discussing this experience, the authors outline the goals and steps they took in developing the Cornelius B. Gold project, an extended, class-based series of assignments that culminated in the production of a digital exhibition (https://ccstudentexhibits.omeka.net/exhibits/show/goldjournal). After two iterations of the project, the team identified a number of unexpected lessons and takeaways; as such, it provides a useful model for future collaborations with similar resources and goals.

\section{Literature Review}

At many liberal arts colleges, digital humanities and digital scholarship efforts have deep links to pedagogical practices (Alexander and Davis 2012, Bonds 2014). While the literature of digital humanities does not often focus on pedagogy--as Brier points out, "teaching and learning are something of an afterthought for many DHers"--there are examples in the literature of faculty incorporating digital humanities-related projects into their classes using off-the-shelf tools, such as Omeka (Brier 2012, 390-391). Klein, working with students at Macaulay Honors College at CUNY, found that Omeka made digital humanities projects accessible to undergraduate students, connecting this emerging field with digital pedagogical practices such as collaboration, experimentation of digital tools, and creativity (Klein 2011). Over a period of three years creating Omeka exhibits with students, Marsh at the University of South Carolina observed that students lacked critical digital skills and, in response, created assignments to help students gain technological and digital storytelling skills. She describes the resulting exhibitions as "disastrous" but states that "as a pedagogical device, the assignment has been tremendously 
successful." She argues that solid pedagogy and student learning may not result in beautiful, professional quality digital projects but that students can still benefit tremendously from the experience (Marsh 2013, 280).

In many case studies, collaboration plays a critical role in the success of digital projects and the effective use of archives and special collections. This is not surprising--collaboration is, many believe, "a necessity in Digital Humanities" (Klein 2015). For example, Bunde, Engel, and Feid at New York University attribute successful course projects that require the use of special collections materials to faculty-library collaboration and the alignment of their goals (Bunde, Engel and Feid 2012). Similarly, a team of librarians and faculty at the University of Kansas implemented an Omeka project in a graduate-level class and concludes that such projects require regular communication and strong collaboration between team members (Rosenblum et al. 2015). Additional case studies position collaboration as a critical factor in student learning when using archives and special collections (Mazella and Grob 2011, Losoff, Sinkinson, and Newsom 2012).

In addition to collaboration, pedagogical shifts accompany the implementation of digital projects. An inquiry approach, for example, shifts the traditional show-and-tell approach to an active learning pedagogy where librarians model scholarly work and guide students through their own projects (Mazella and Grob 2011). Active learning opportunities can turn archives and special collections into a "research laboratory in which students polish their archival research skills and learn techniques for writing for diverse scholarly and public audiences" (Schmiesing and Hollis 2002, 466). Vong recommends a constructivist pedagogy that situates the instructor and librarian as guides, while students take responsibility for their learning by engaging in dialog, hands-on work with sources, and reflection (Vong 2016). By creating opportunities for 
students to engage and make meaning from the materials in archives and special collections, Smith argues we can benefit both the student and the collections: "by finding ways to bring our collections to the classroom and the classroom to our collection, we help educate future generations about the importance of primary records while advancing our mission to preserve the raw materials of research" (Smith 2006, 36).

Newly adopted pedagogies can create opportunities for students to directly engage with primary sources available through college special collections and archives, then create new knowledge and share it broadly: "when students have structured opportunities to construct meaning from primary materials, and critically examine those meanings, they feel more invested in the results" (Tally and Goldenberg 2005, 16). In the design of such experiences, however, faculty, librarians, and instructional technologists cannot ignore students' previous experiences and levels of technological proficiency when designing such assignments. The overconfidence among many students today in their technological ability is well studied and documented (Helsper and Eynon 2010). At the same time, the digital revolution and the growing profusion of information on the Web has driven a tectonic shift in the way college students want to interact with knowledge. Investigating student relationships with research and the library, some scholarship has emphasized a growing preference for creating, or actively making things, and not just consuming or passively studying things, when it comes to interacting with new knowledge (Austin et al. 2011; Bagley 2012; Scott 2012). Likewise, Accart (2013) has found that with the rise of social media, millennials are seeking a more active or participatory role in the creation of knowledge. Given such research on the "purpose-driven" millennial generation, the faculty aimed to address student preferences not only to pursue "meaningful" work, but also create 
value, or a product that "improves society" (McGlynn 2008; Sweeney 2006; Winograd and Heis 2014).

\section{Institutional Context \& Technology Fellows Program}

Connecticut College is a private, residential liberal arts college located in New London, Connecticut. The college offers fifty-six majors, minors, and certificates to 1,900 students. There is a strong culture of teaching and learning among faculty, supported by campus resources like the Center for Teaching and Learning (Hanc 2016). In 2014, a new program was created inviting faculty applicants to explore, experiment with, and implement new digital technologies with the goal of improving teaching and learning at the College. Now in its fourth year, the Technology Fellows Program (TFP) continues to receive strong support from the Dean of the Faculty and the Vice President of Information Services and Librarian of the College (McCullough 2016). The program is led by two faculty members in collaboration with staff from the library's Instructional Technology team.

Selected faculty spend three semesters as Tech Fellows. Participation requires that faculty attend and contribute to Teaching with Technology workshops organized by Instructional Technology, learn about new technologies and resources that may help them accomplish pedagogical goals, meet regularly as a group with librarians and instructional technologists for discussions, and develop new assignments and methods of assessment. Eventually, they integrate their methods and lessons into their courses, workshop their ideas, and then share their results with local and regional communities through regular posts in the Instructional Technology blog, Engage (https://teachtechconncoll.wordpress.com/). Tech Fellows also serve as discussants at local teaching and learning discussions and seminars, make presentations at regional conferences, or write articles such as this one. An innovative aspect of the program is that 
faculty in their third, and final, semester in the program serve as mentors for incoming fellows. Tech Fellows are motivated to participate for several reasons: not only is it an honor to participate, but the TFP offers stipends for each semester of participation and a one-course remission during the second semester of planning. The program thus gives significant institutional support and time to faculty who demonstrate a strong desire to explore and collaborate on digital scholarship in the classroom

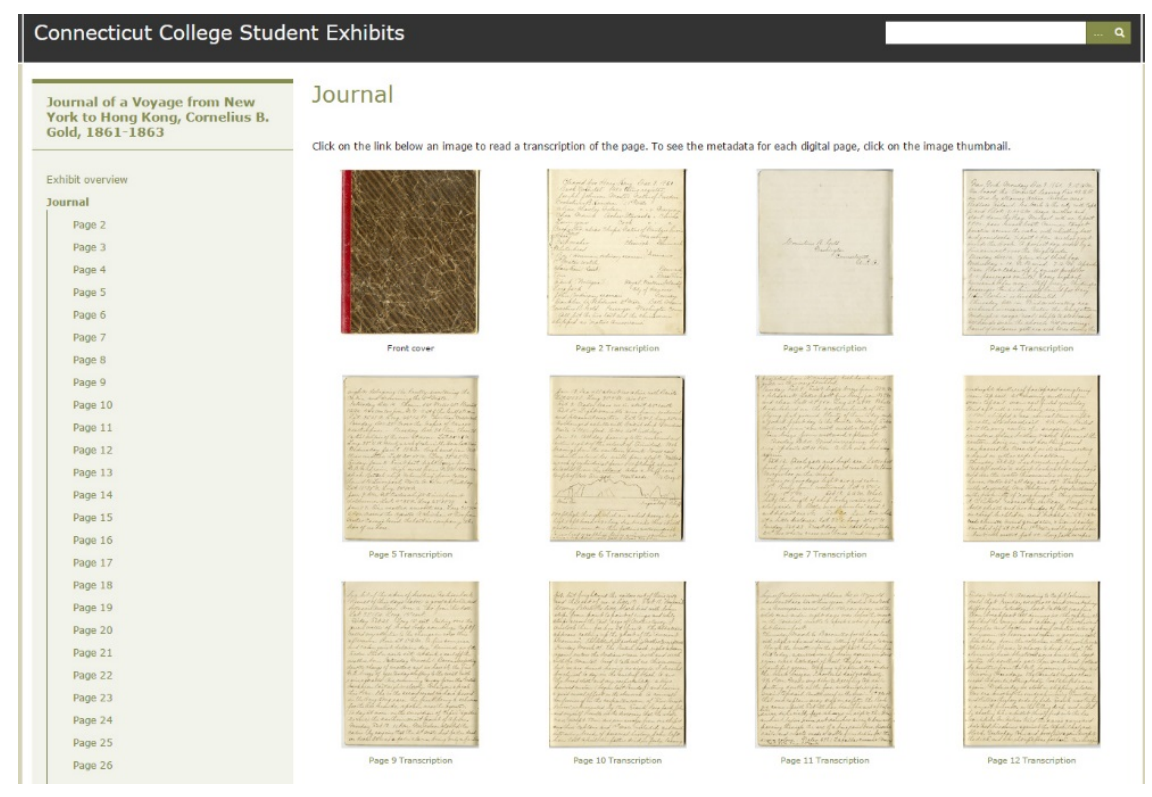

Figure 1. In the main overview of the Cornelius Gold digital exhibition, users can navigate through the journal on a page-by-page basis. Links under the images take visitors to a detailed view of each transcribed and annotated page.

\section{The Cornelius B. Gold Project: A Case Study in Digital Learning and Engagement}

In the first year of the TFP, five faculty fellows were selected to collaborate with Instructional Technology librarians and affiliated library staff to develop and implement new digital curricula in their courses. The five fellows represented a broad range of departments and interdisciplinary affiliations including anthropology, art history, German studies, history, and psychology. While 
the faculty were initially tasked with integrating one new digital assignment into a preexisting course, most developed renewable projects that they could later extend or replicate in future courses.

One such project was the case study presented in this article: the Cornelius B. Gold digital exhibition, which featured Gold's travel journal in East Asia in the early 1860s.

Implemented over an extended period of time, the project involved a series of scaffolded student assignments, which the faculty fellow, an Assistant Professor of History, undertook in collaboration with an instructional technologist from the library and two staff from the Linda Lear Center for Special Collections and Archives (LCSCA). A separate subject liaison librarian also joined the project briefly, providing research support as students drafted exhibit essays later in the semester. This collaborative framework, bolstered by the institutional support of the college, was at the core of the project's initial development, ensuing assessments and revision, and final outcomes.

\section{Goals and Rationale of Project Collaborators}

Given broad institutional support to experiment and innovate, the project team was fundamentally motivated to collaborate by the overlapping and complementary goals of its individual members. Each of the participants aimed to generate new student learning opportunities for critical inquiry and analysis. In connecting students with digital tools to share information and research about special collections, the project offered a unique opportunity to engage students as active producers of knowledge (rather than passive consumers) in the classroom and beyond. Through original research with special collections, the students would create a new and valuable resource for scholars and enthusiasts around the world. 
These general and overlapping goals provided a meaningful framework for collaboration. The course instructor agreed with library and LCSCA staff that a digital project could enhance student learning by giving students ownership of the research process. The project also provided a unique context for reinforcing course themes on modern imperialism in East Asia. Its focus on a nineteenth-century travel journal suited disciplinary objectives in history to teach students to read and evaluate primary sources as evidence. Thesis-based writing and annotation assignments further supported broader objectives in the humanities to strengthen student rhetorical skills, including the ability to synthesize primary and secondary data.

LCSCA staff brought complementary objectives to the project, including institutional goals to share and democratize access to knowledge. The creation of a public, online exhibition promised to raise the profile of Lear Center collections and to make the history of Cornelius Gold more accessible and engaging to all. LCSCA staff were also keen to develop extended class-based projects as a way to foster community engagement with library resources and collections. The project's implementation of digital technologies to develop an online presence for the Gold journal presented them with a meaningful opportunity to create greater access and exposure to archival collections.

The Instructional Technologist joined the project with the aim to observe and test new applications for the Technology Fellows Program at Connecticut College. The Gold project was an opportunity to explore the applicability of emergent tools and digital technologies in promoting student engagement, academic inquiry, and knowledge and research literacies. As a participant in the project design, the technologist could also share professional insights while building more productive relationships with faculty and students. 
In sum, for all team members, the decision to work collaboratively provided a critical framework for developing the project and a basis for exploring future digital scholarship initiatives. While their rationale for participating was essentially aligned, their various professional and disciplinary obligations allowed them to appreciate the project from multiple perspectives, assess its successes and failures, and make various adjustments toward more positive outcomes.

\section{Project Overview and Description of the Gold Journal}

In spring semester 2015, the faculty fellow and students in the course "Empire and Expansion in East Asia, 1840-1950s" worked with the Linda Lear Center for Special Collections and Archives to create a virtual exhibition of the journal of Cornelius B. Gold, a young man from Connecticut who sailed on board a merchant vessel from New York to the South China Sea between 1861 and 1863.

After being denied entry to the Union army due to poor health, Gold set sail for Hong Kong on the merchant vessel Oriental in 1861, with the hope that a voyage at sea would strengthen his condition and prepare him for military service upon his return. Over the course of his 15-month journey, Gold documented his travels in Malaysia, Indonesia, China, and the Philippines in a sixty-three-page diary, providing invaluable insight into his experiences, impressions, and cultural encounters as he traveled the globe.

LCSCA acquired the Gold journal in the summer of 2014, building on a collection of Gold's later Civil War correspondence already held by the center. The newly acquired journal was brought to the attention of the faculty Technology Fellow as a potential resource for her courses in East Asian History. Prior to this, the faculty fellow had worked with LCSCA in 
introducing other relevant collections to students and encouraging their use of rare books and manuscripts in smaller course projects.

The project team, comprised of the faculty fellow, LCSCA staff, an instructional technologist, and a research librarian, worked to devise a structured project, which enabled students to conduct disciplinary research and experiment with digital technologies through a semester-long series of scaffolded, interrelated assignments. The assignments comprised transcribing and annotating the journal, and mapping Gold's voyage across the globe. Informed by course content on the history of trade and empire in East Asia, students further explored specific aspects of the maritime industry, international trade, and nineteenth-century East-West relations, publishing their independent research in short critical essays to accompany the digital exhibition.

\section{Navigating the Gold Exhibit: Project Planning and Tools}

In the semester prior to the course, the project team made a series of administrative and technical decisions aimed at incorporating the students as stakeholders in the exhibit and facilitating productive engagement with the manuscript journal. One of the first decisions was to host the exhibition on Omeka, an open source web-publishing platform developed by George Mason University's Roy Rosenzweig Center for History and New Media that has become popular among cultural heritage organizations, as it allows users from a range of technological backgrounds to easily build digital collections and professional web exhibitions. The ease-of-use of Omeka allowed the project team to establish the exhibition framework with minimal need for technical support, enabling students to devote their attention to content and interpretation without the additional task of coding a website. Another key feature of Omeka was its use of the Dublin 
Core metadata schema, which opened the door for sophisticated conversations with students about the power of descriptive language in making materials accessible to a global audience.

The project team further made critical decisions about the structure and rationale: how to deliver pertinent background knowledge to students; how to explain the rationale for creating an online digital exhibition; and how to divide the project into a series of assignments that were feasible and appropriate for a 14-week undergraduate history course. The project team took a scaffolded approach, separating it into four successive phases which carried students from an introduction to the project and manuscript research through to the final public launch of the exhibition.

In phase one, students were introduced to project goals, manuscript research, and the Cornelius Gold collection. In phase two, students began building the digital exhibition in Omeka. Students completed and posted their research essays illuminating facets of the Gold journal in phase three and formally launched the site and presented their work in phase four.

Throughout the course of the semester, the project team communicated frequently on scheduling and project orientation, discussing the project's progress and schedule, standards for publication, and evaluation criteria and methods. The frequency of these planned check-ins was critical in fostering a greater sense of collaboration and collegiality among the project team.

\section{Project Timeframe and Assignments}

Phase One: Preparing for Archival Research

In the first phase of the project, students spent several weeks exploring the development of trade and diplomatic relations between Euro-American powers and East Asian countries. The Gold journal was introduced in this context of the steady rise of European imperialism in East Asia from the eighteenth to mid-nineteenth century. Learning the historical forces that were driving 
Euro-American expansion in Asia was essential in setting the stage for students to better appreciate Gold's observations while traveling on a cargo ship from New York City to Hong Kong in the 1860 s.

At the first project meeting LCSCA staff introduced students to concepts of special collections and archives and primary source research. Students were given the opportunity to handle and discuss the manuscript journal. They were also shown examples of successful digital exhibits, and they held a discussion on key features that they would consider for inclusion in the Gold exhibition.

The class was divided into groups and assigned a section of the journal to read, transcribe, and annotate. Before embarking on their group transcriptions, students worked with LCSCA and library reference staff to become familiar with the conventions of nineteenth century handwriting, narrative structure, and maritime vocabulary, and to identify relevant reference sources and to develop research strategies they could use to decipher and analyze the text. LCSCA staff further gave students examples of useful annotations and explained the impact of clear, carefully researched textual notes on readers' ability to gain a richer understanding of the material.

Phase Two: Designing the Omeka Exhibit

Under the guidance of the project team, students finalized the general design of the digital exhibition. LCSCA staff developed a template and wireframe for the exhibition in Omeka, which provided students with a low-barrier entry to gain basic experience in web design and to experiment with digital humanities tools. Omeka's suite of built-in tools enabled students to present the journal both as object and research resource, and to gain experience in exhibition design, structuring of content, visualization of data, and basic Web coding. 
Over the course of several weeks, the project team worked with students to design the exhibition and to develop necessary technical skills to carry out the bulk of the work with minimal supervision. The class designed the site to display each page of the journal in succession, enabling users to read the journal as a manuscript or as an exact transcription. Students further coded the transcription so that users could simply hover over a highlighted word to view the corresponding annotation and reference. Using geographic mentions and explicit navigational recordings in Gold's journal, students tracked Gold's voyage through each page of the text, entering coordinates on a map plugin attached to each transcription so that users could follow the journey's progression across the globe.

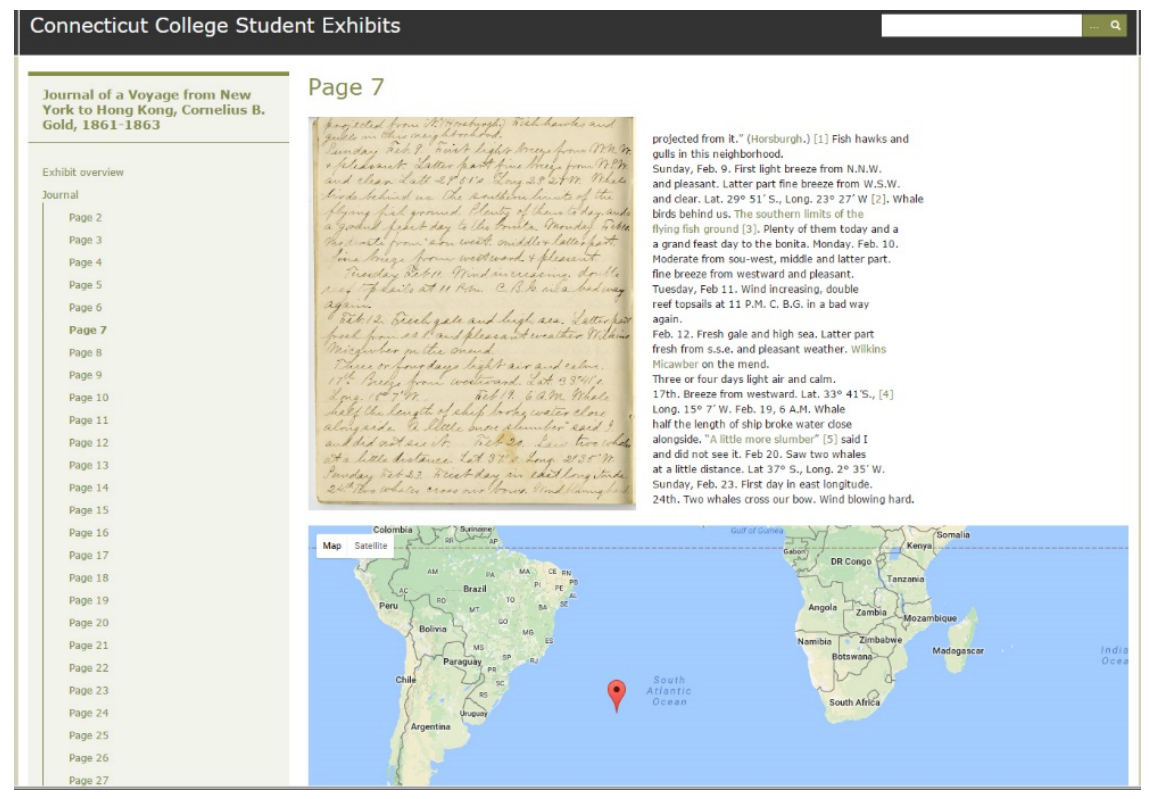

Figure 2: Detail view of a page from Cornelius Gold's journal. Navigational recordings enabled students to plot the voyage of the Oriental using an Omeka map plugin.

Phase Three: Developing Research Essays

As students worked to construct the digital exhibition, they continued to analyze the journal, contextualizing Gold's observations through overarching course themes and past reading assignments and discussing ways in which they could help visitors to the exhibition better 
understand and appreciate the content of the journal. Students were broken into groups to develop research topics that connected to journal themes: nineteenth-century shipping practices, the origins of overseas banking and finance, international sex trafficking in the Pacific Rim, and U.S. missionary, diplomatic, and tourist activities in East Asian treaty ports, among others.

Students consulted subject librarians to develop a bibliography and write an essay of approximately 1000 to 1200 words explicitly tying their research to passages in Gold's journal. Each group had two weeks to compile their bibliographies, and after consultation with the professor, an additional two weeks to complete their essays. In addition, each group was asked to compose a brief, engaging introduction to the digital exhibition, the favorite of which would be used in the final Omeka site.

Over the course of two meetings, students revised and perfected their work, launched the website, and assessed the exhibit. The class engaged in a peer review process in which students read each other's essays and helped each other to strategize how and where to shorten their topical essays. Because the ultimate goal of the assignment was to produce content for a digital exhibition, the instructor emphasized the impact of succinctness, and challenged students to trim their essays by roughly twenty-five percent. In contrast to more typical writing assignments for humanities courses, the exhibit essays needed to be informative yet short--designed for an online audience.

Phase Four: Assessing the Exhibit Impact

The Gold project concluded with an end-of-term celebration and public symposium during the final class session. At the library's visualization wall, students presented the digital exhibition and their research findings to an audience of classmates, librarians, and staff. Faculty from 
several departments also attended to learn about the potential for student research in the context of the intersection between collaborative pedagogy and digital scholarship.

The final symposium was an important opportunity for students to view and interact with the final exhibition in a public setting. The open discussion period following the student presentations also allowed them to continue making important connections between the Gold journal and overarching course themes about the global history of trade; in discussing their work with the campus community, students gained a broader understanding of the impact and implications of their work.

The discussion period also enabled students to quantify the impact of their work. Using Google Analytics, students were able to track user behavior (time spent on the site, bounce rate, pages viewed, etc.), and to demonstrate the broad engagement of their research by an international audience, particularly from countries referenced by Gold throughout his voyage. 


\section{Audience Overview}

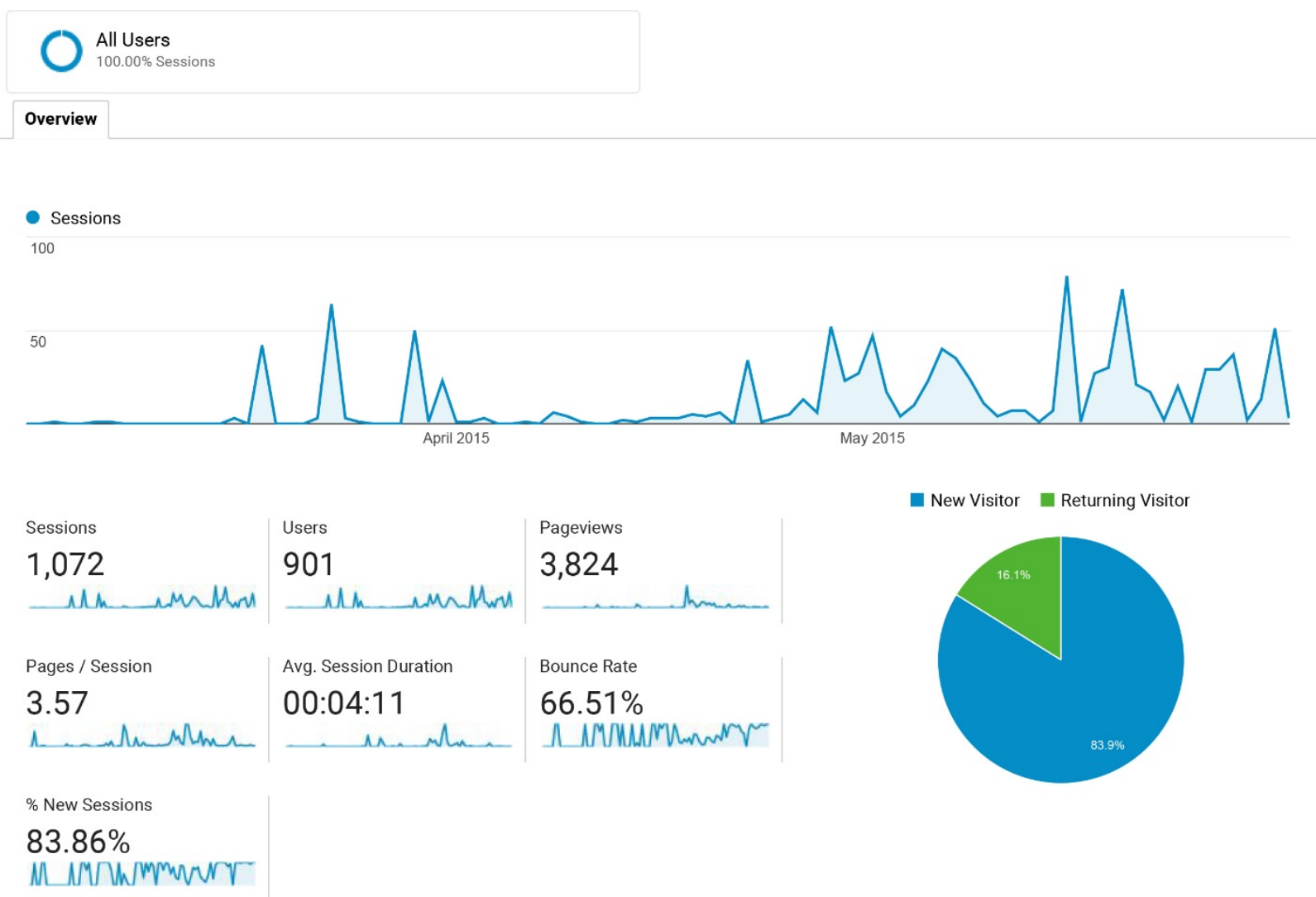

Figure 3: Google Analytics report indicating audience behavior in the first twelve weeks after launch, including the number of users and user sessions, the bounce rate, and the average time spent on the site.

Following the symposium, students completed final exams and wrote reaction essays describing their most salient course learning experiences. Student outcomes were assessed from data collected from surveys, final exams, and evaluative comments during class, private communications with instructors, and in end-of-semester reaction essays. Based on this data, the collaboration chose to undertake a second round of the project with a new cohort of students in the same class in the fall of 2015. 
What follows is first, a discussion of challenges encountered and lessons learned from the first offering of this course, and second, a summary of modifications that the collaboration made for the second round of the project.

\section{Summary of Results}

\section{Challenges}

The project team encountered several challenges over the course of the semester, including evaluation of students' work, effective communication about the project's role in overall course objectives, and constraints of integrating a significant project into the workload of an existing semester-long course.

Of these challenges, evaluation was the most difficult to resolve. As the project represented a departure from traditional assignments in the humanities, the team struggled to devise and communicate clear criteria for evaluating project assignments. Critically, the project team underestimated the technical and conceptual difficulties presented by the assignment. Students became frustrated with the relatively slow work of parsing a cursive hand, and struggled to produce accurate transcriptions and insightful annotations, preferring to create annotations that defined unfamiliar language or phrasing over ones that provided deep contextual, historical, biographical, or geographic information. Presented with these challenges, the project team attempted to strike a balance between rewarding effort, students' desire for transparency in the evaluation of their work, and the need to produce a professional, accurate final product.

In response to student desire for clear evaluation criteria, the project team developed a grading rubric. The rubric stressed the experimental, "low-stakes" nature of the work--that the point of the assignment was in part to try something new and to engage with history in different 
ways. Accordingly, evaluation was grounded in the following basic criteria: timely completion of the transcription and at least twelve annotations, clear evidence of engagement with the material, and use of library resources, including consulting LCSCA staff. Further, the rubric emphasized that accuracy was not necessarily the final determinant of quality. Evaluating student work according to this rubric was a two-pronged approach; as subject-matter experts, LCSCA staff undertook the initial content evaluation, while the instructor assessed each group's efforts according to course objectives.

While designed for maximum flexibility in accounting for a wide range in students' skills, this mode of evaluation had some drawbacks. As designed, the rubric may have established a lower standard than some students might have otherwise achieved. And although LCSCA staff did not formally grade the students' work, they provided the faculty fellow with qualitative feedback by assessing the sophistication of the transcriptions and annotations. While this was helpful for the professor, some students were uncomfortable with the idea of being evaluated by someone other than the course instructor.

A second challenge involved the effective communication of the relationship of project assignments to the final digital exhibition. During the project's design phase, the team decided to divide the manuscript into sections for students to work on in small groups for the sake of manageability. As such, each group completed their work in isolation from one another and did not encounter the full manuscript as a coherent narrative until much later in the project. Some students remarked that they perceived the level of difficulty in transcribing and annotating the various sections as unevenly distributed. Although LCSCA staff attempted to divide the journal in thoughtful and equitable ways, a couple of students voiced frustration that the assignments were "unfair." More significantly, many struggled to draw a connection between their group 
efforts and the resulting exhibition and to see the relevance of their work to the project as a whole. In this regard, the project team failed to effectively convey the collaborative value of the project, and students thus failed to grasp the logic behind working toward a common goal. This problem negatively impacted some students' motivation and enthusiasm during the earliest days of the project.

A final challenge lay in the nature of inserting an ambitious project into the timeframe of an already constrained course. The tight timeframe and scaffolding of assignments (transcription, annotation, research, and exhibit construction) left little opportunity for students to review their mistakes and consider ways to edit or make improvements to their transcriptions and annotations. It also limited their ability to continue to build their skills in manuscript analysis, as they did not have the time to become comfortable with nineteenth-century script or to familiarize themselves with the full range of secondary reference resources necessary for sophisticated annotation.

\section{Student Surveys}

As the project came to an end, student surveys conducted one week before the final class revealed that roughly forty-five percent of the class felt enthusiastic or energized; roughly twenty percent of the class was openly indifferent; and roughly fifteen percent felt negatively about the project. Approximately one-third of the class, most of whom were in their fourth year, voiced displeasure in having to engage in unconventional assignments like annotation and transcription. Students' inability to recognize the importance of these assignments to the overall project was a source of frustration for many.

Despite the mixed responses in the initial survey, more positive feedback surfaced after LCSCA staff presented preliminary data from Google Analytics outlining the global impact of the Gold exhibition only three weeks after its launch. This presentation became an unexpected 
turning point for students, as it provided them with concrete data reflecting the implications of their work. Moreover, it demonstrated the success the students had achieved in combining their efforts to create a final product: a complex, collaborative digital exhibition that was attracting a number of users worldwide. Another turning point occurred during the final class meeting, in which students presented their work to faculty, staff, and fellow classmates, and participated in an open Q\&A about the exhibit. The series of oral presentations and ensuing conversation provided the students with their first opportunity to discuss the exhibit in its entirety. In addition, the public nature of the open house allowed students to observe the enthusiasm their project was generating among the campus community.

Student satisfaction with these results were ultimately reflected in open-ended reflection essays, submitted during finals week. Many wrote about the connections they made with the Gold project to lessons learned in other parts of the course and more broadly in other classes. Among the most recurrent themes were their pride in having completed original research, satisfaction in creating a permanent and professional product, and observations that they learned in new and different ways.

\section{Project Round \#2: Revisions and Improvements}

In analyzing the culmination of student feedback and assessments of project goals, the project team concluded that this collaborative effort, though imperfect, was a valuable experience for students and the project team alike. The team was pleased overall with the success of the project, but acknowledged that there were improvements that could be made to the exhibition as well as to the management of the project. The team therefore decided to introduce a slightly modified version of the project for a second iteration of the course in the following semester. 
Based on feedback and classroom observation, the project team determined that several adaptations needed to be made, including modifying the overall time frame; impressing upon students at the outset the real, immediate impact that projects like these could have in communities well beyond campus; focusing on the manuscript as a complete narrative before dividing it into discrete sections; and discussing examples of successful, cogent digital exhibit annotations. The team decided to shorten the time frame to allow students to focus on fewer tasks and to delve more deeply into them. It also rearranged the timing of key discussions and assignments in several significant ways.

In the first collaborative meeting, the team tried to emphasize the rationale behind the project by introducing the students to user statistics collected in Google Analytics. User data from the Gold exhibit indicated an unexpectedly high level of user engagement: in the six months between the end of the first project and the beginning of the second iteration, the site had been visited by nearly 4,000 users who spent an average of six minutes paging through the exhibition. Visitors were especially well-represented among countries corresponding to the regions where Cornelius Gold had visited on his travels--China, Malaysia, and the Philippines-as well as among other countries in East and Southeast Asia, including Japan and South Korea. In sharing this data with the students at the outset, the project team aimed to headline for the students the value the Gold project had in concrete terms for a large network of global users. 


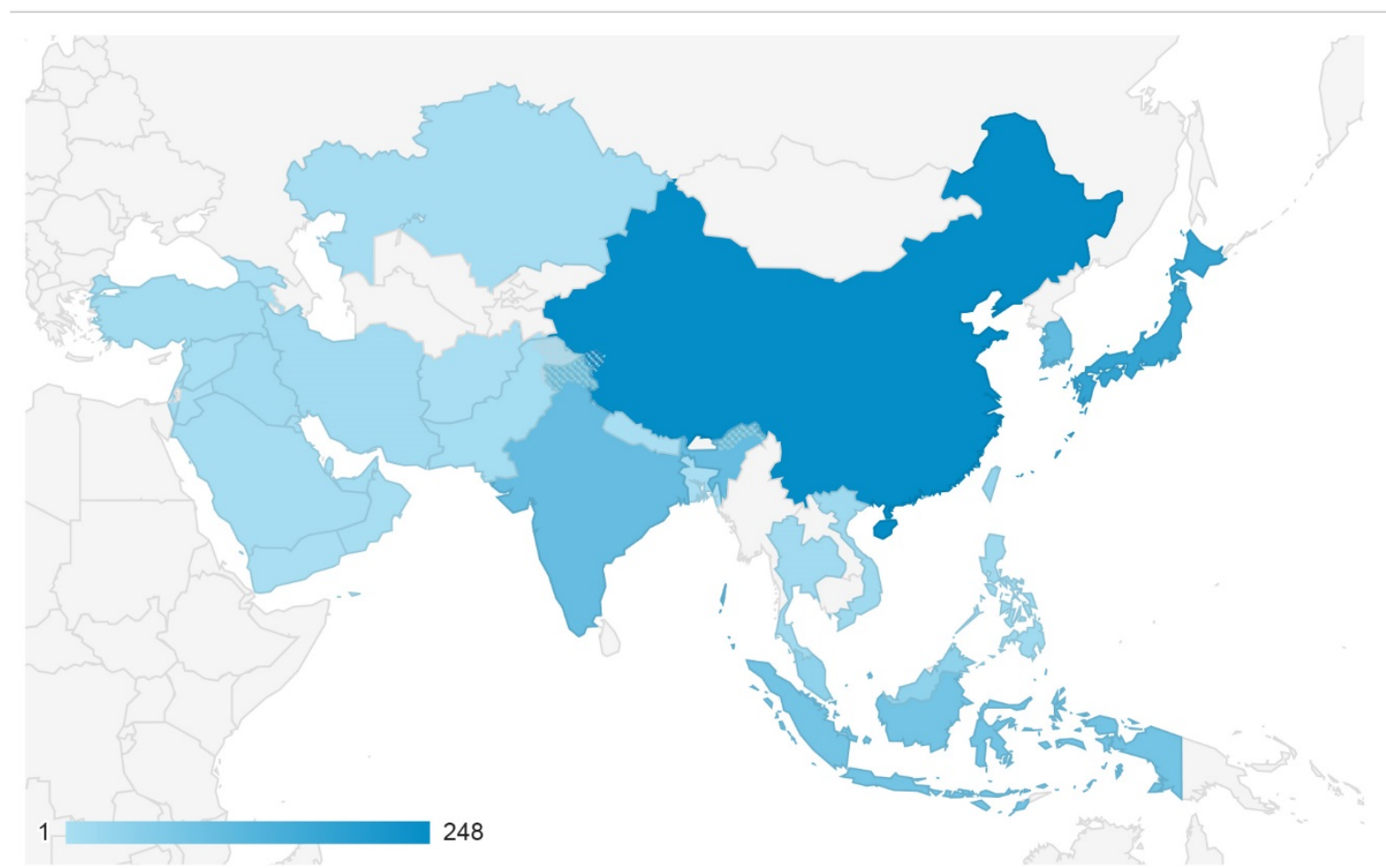

Figure 4: Google Analytics map indicating user location in Asia, March 2015 to January 2017

Another significant revision to the project schedule was the decision to introduce the entire manuscript at the outset of the project. The team determined that assigning the journal early in the semester would better integrate it into course objectives, enabling students to assess it in the context of course themes from the outset. Students were further asked to identify excerpts that were potentially confusing or unclear, which in turn became a useful launching point for discussions about annotating the journal with LCSCA staff.

A third key modification to the project was the decision to omit the transcription exercise entirely and emphasize annotation work that was deeper and more intentional. Consequently, the team spent more time identifying and discussing the characteristics of strong annotations, showing examples of particularly successful work constructed by the previous class as well as areas that could benefit from deeper research. The team encouraged the students to treat their annotations like scaled-down research papers, gave them four weeks to complete the work, and 
required check-ins with LCSCA staff midway through the process to discuss their progress. Upon the completion of their annotations, students engaged in a brainstorming session to develop topics and themes within the journal for further research. The project team encouraged students to consider developing some of the more complex annotations into broader research subjects. In the last collaborative session, the students once again presented their work to the campus community, using updated statistics from Google Analytics to demonstrate the impact of their site on a global audience. At the conclusion of the second iteration of the project, it was clear from formal and informal feedback that students were more invested in and engaged with the project, more satisfied with the course overall, and more readily able to connect project themes with course learning objectives.

\section{Project Implications}

The opportunity to integrate a digital scholarship project over two semesters in the same course provided an invaluable experience for the project team. Through the process of planning, evaluation, and reassessment, the team was able to draw tentative conclusions about the elements of a successful, student-focused digital scholarship project, leading to several implications that may help to guide future collaborations.

While collaboration doesn't happen seamlessly, fostering connections between library and teaching professionals yields substantial personal, professional, and pedagogical benefits.

Working together in an intentional, dedicated way enabled the project team to strengthen individual and departmental relationships. While faculty and librarians serve complementary roles, strong institutional and programmatic support for collaboration enabled the team to better appreciate the particular knowledge and competencies each member brought to the process. The 
successes born of this collaboration encouraged LCSCA staff to think more ambitiously and intentionally about potential work with faculty; correspondingly, faculty have an enhanced view of the library and its collections as a teaching and research resource. In the two years since the conclusion of the project, there has been a marked increase in faculty demand for intensive primary source-based digital projects. Nine faculty from a range of disciplines have worked with the Lear Center to develop digital projects centered on the exploration of special collections and archives materials. This model has become a significant pedagogical tool to teach students primary source research skills.

The project has had other benefits as well. College administration has highlighted this collaboration as an important advantage of a small, undergraduate-focused liberal arts education. Working together enabled teaching faculty and librarians to bring a complex project into the classroom experience, and to involve students in a concerted process of knowledge creation. By its nature, digital scholarship involving unedited primary source manuscripts demands input from a wide array of skills and competencies; through this project, the team was able to highlight the necessity of collaboration in creating a substantial resource of lasting value to researchers.

It is critical for students to gain an understanding of the primary source as a document and within the context of the course as early in the process as possible.

In the first semester, students encountered the journal in a piecemeal fashion, and accordingly lost the context of the manuscript as a coherent narrative. In turn, this hindered their ability to understand the journal in the context of course themes and objectives. In the second iteration, when students were able to read the journal early in the semester, they were better prepared to conduct primary source analysis and to appreciate its role as an historical account. 
Students seem to have little previous experience with engaging in digital scholarship, and consequently require clear, concrete models of successful digital projects and an explicit understanding of the connection between their own work to the final project as a whole.

Over the course of both iterations of the project, the team discovered that describing the intended project in detail to students was largely ineffective; rather, students needed concrete examples on which to model their work. Upon seeing samples of other digital exhibitions and an example of the project to which they would be contributing, students gained a better understanding of the rationale behind the individual assignments. Accordingly, they were more ambitious, more engaged with the assignments, evidenced a higher overall degree of satisfaction with the project, and easily met project goals.

For courses like these, in which the digital project is a substantial assignment but not the focus of the semester, the project team would recommend building a significant portion of the digital project ahead of time, as it will assist both in the modeling of the exhibition and in focusing students' efforts.

A demonstrable method of evaluation and tools to measure impact help communicate the significance of the project and increase overall enthusiasm.

Initially, students had difficulty conceptualizing the impact of their project in the abstract, as few grasped that their research would reach a public audience. When presented with statistics which showed measurable impact, however, students became more invested in the project and evidenced a high degree of concern over the quality of the exhibition and of their contributions to it. By introducing Google Analytics at the start of the project's second iteration, the project team was able to generate greater enthusiasm from the outset.

Digital scholarship projects are often about the process, not the product 
In the first iteration of the project, the team began by conceptualizing a broad idea of the final product--some sort of digital exhibition featuring the Cornelius Gold journal--and a general sense of the types of skills it wanted students to develop, from strengthening critical reading and research skills to gaining experience in exploring the ways in which digital tools can help mediate, interpret, and present archival materials to a broader community. The project team anticipated that these outcomes could be achieved through a series of skill-building exercises that would bring students from nascent explorations of unmediated manuscript material to the creation of a sophisticated, public digital exhibition.

Inevitably, a tension arose between the project team's vision of the digital exhibition and the specific skills it was trying to develop in students, as some students came to resent certain assignments intended to produce the exhibition (transcription, site design) as pointless "busywork." As a consequence, the team found it important to continually assess and reevaluate what critical skills it was trying to communicate, and to retool its emphasis so that the assignments were focused on those skills it deemed most important for students and most necessary to complete the exhibition. Perhaps the most valuable realization was that the importance of the project was not necessarily in the end product; that a "good enough" exhibition could be a successful project if students gained critical skills from the experience. Students did not need to be fluent readers of a nineteenth-century hand to gain valuable primary source research skills; similarly, students did not have to become programmers to gain skills in digital scholarship.

\section{Conclusion}

Digital scholarship and technology can serve as a powerful mechanism for bringing together diverse groups of faculty, librarians, and technologists to engage students in meaningful research 
using library collections. For the project team, this experience provided an opportunity to explore innovative ways of integrating unedited manuscript materials into the curriculum, teaching primary source research skills while opening collections to a wider audience, and experimenting with new uses of technology in the classroom. For students, the assignments provided a chance to work together as a community of scholars, and to gain hands-on experience conducting research, producing new knowledge, and communicating that knowledge with a global audience.

The collaborative approach to digital scholarship adopted by the project team provided the time and space to think deeply and carefully about the project, to be intentional about its design, to evaluate successes and failures, and to establish new lines of communication among faculty, staff, and students. While there were limited financial and technological resources available for the project, institutional support was nevertheless an important factor in the success of this approach, providing the necessary flexibility for both faculty and staff to work together. Connecticut College's Technology Fellows Program encouraged faculty to implement technology in the classroom by giving them time to experiment, plan, and assess project outcomes through a course remission, stipends, and access to training and support. Meanwhile, library administration gave LCSCA and Instructional Technology staff the flexibility to work extensively with faculty to plan and implement a successful digital scholarship project.

After two iterations, the team learned valuable lessons about project sequencing and planning, communicating the project's value and impact, and engaging students throughout the process. While many of the project's best lessons and achievements were the products of team collaboration, perhaps the most positive outcome was in providing students an opportunity to 
engage in the active, participatory nature of digital scholarship: working closely together to create a project with impact on campus and beyond.

\section{References}

Accart, Jean-Philippe. 2013. "Hot off the Press! Fab labs and libraries." Library Hi Tech News 30 (7). doi: http://dx.doi.org/10.1108/lhtn.2013.23930gaa.001

Alexander, Bryan, and Rebecca Frost Davis. 2012. "Should Liberal Arts Campuses Do Digital Humanities? Process and Products in the Small College World." In Debates in the Digital Humanities, edited by Matthew K. Gold, 368-389. Minneapolis: University of Minnesota Press.

Austin, Kimberly, Stacy B. Ehrlich, Cassidy Puckett, and Judi Singleton. 2011. YOUmedia

Chicago: Reimagining Learning, Literacies, and Libraries: a Snapshot of Year 1. Consortium on Chicago School Research at the University of Chicago Urban Education Institute. http://ccsr.uchicago.edu/downloads/6899youmedia\%5Ffinal\%5F2011.pdf

Bagley, Caitlin A. 2012. "What Is a Makerspace? Creativity in the Library." ALA TechSource, December 20. http://www.ala.org/tools/article/ala-techsource/what-makerspace-creativitylibrary

Bonds, E. Leigh. 2014. "Listening in on the Conversations: An Overview of Digital Humanities Pedagogy." The CEA Critic 76 (2): 147-157. 
Brier, Stephen. 2012. "Where's the Pedagogy? The Role of Teaching and Learning in the Digital Humanities.” In Debates in the Digital Humanities, 390-401. Minneapolis: University of Minnesota Press.

Bunde, Janet, Deena Engel, and Paula Feid. 2012. “Computing in the Humanities@NYU Libraries.” In Past or Portal? Enhancing Undergraduate Learning through Special Collections and Archives edited by Eleanor Mitchell, Peggy Seiden, and Suzy Taraba, 119-124. Chicago: Association of College \& Research Libraries.

Hanc, John. 2016. “Teaching Professors to Become Better Teachers.” New York Times, June 23. https://www.nytimes.com/2016/06/23/education/teaching-professors-to-become-betterteachers.html?_r=1

Helsper, Ellen Johanna, and Rebecca Eynon. 2010. "Digital Natives: Where is the Evidence." BERJ: British Educational Research Journal 36 (3): 503-520.

Klein, Julie Thompson. 2015. Interdisciplining Digital Humanities: Boundary Work in an Emerging Field. Ann Arbor, MI: University of Michigan Press.

Klein, Lauren. 2011. "Hacking the Field: Teaching Digital Humanities with Off-the-Shelf Tools." Transformations: The Journal of Inclusive Scholarship and Pedagogy 22 (1): 37-52. 
Losoff, Barbara, Caroline Sinkinson, and Elizabeth Newso. 2012. "Special Collections

Instruction in the Sciences: A Collaborative Model.” In Past or Portal? Enhancing

Undergraduate Learning through Special Collections and Archives, edited by Eleanor Mitchell,

Peggy Seiden, and Suzy Taraba, 137-141. Chicago: Association of College \& Research

Libraries.

Marsh, Allison C. 2013. "Omeka in the Classroom: The Challenges of Teaching Material Culture in a Digital World." Literary and Linguistic Computing 28 (2): 279-282.

Mazella, David, and Julie Grob. 2011. "Collaborations between Faculty and Special Collections Librarians in Inquiry-Driven Classes." portal: Libraries and the Academy 11 (1): 467-487.

McCullough, Jessica. 2016. “Technology Fellows Program Sees Growth, Innovation.” Inside Information: Newsletter of Information Services at Connecticut College. http://www.conncoll.edu/media/website-media/is/IS-2016-Spring-Newsltr_Final.4.pdf

McGlynn, Angela Provitera. 2008. "Millennials in College: How Do We Motivate Them?" Education Digest: Essential Readings Condensed for Quick Review 73 (6): 19-22.

Rosenblum, Brian, Frances Devlin, Tami Albin, and Wade Garrison. 2015. "Collaboration and CoTeaching: Librarians Teaching Digital Humanities in the Classroom." In Digital Humanities in the Library: Challenges and Opportunities for Subject Specialists edited by Arianne Hartsell- 
Gundy, Laura Braunstein, and Liorah Golomb, 151-175. Chicago: Association of College and Research Libraries.

Scheinfeldt, Tom. 2010. "Stuff Digital Humanists Like: Defining Digital Humanities by its Values,” December 2. http://foundhistory.org/2010/12/stuff-digital-humanists-like/

Schmiesing, Ann, and Deborah Hollis. 2002. "The Role of Special Collections Departments in Humanities Undergraduate and Graduate Teaching: A Case Study.” portal: Libraries and the Academy 2 (3):465-480.

Scott, Sarah Hashemi. 2012. "Making the Case for a Public Library Makerspace," November 11. http://publiclibrariesonline.org/2012/11/making-the-case-for-a-public-library-makerspace/

Smith, Steven Escar. 2006. 'From 'Treasure Room' to 'School Room': Special Collections and Education.” RBM: A Journal of Rare Books, Manuscripts, and Cultural Heritage 7 (1):31-39.

Sweeney, Richard. 2006. "Millennial behaviors and demographics.” Newark: New Jersey Institute of Technology. https://certi.mst.edu/media/administrative/certi/documents/ArticleMillennial-Behaviors.pdf.

Tally, Bill, and Lauren Goldenberg. 2005. "Fostering Historical Thinking with Digitized Primary Sources.” Journal of Research on Technology in Education 38 (1): 1-21. 
Vong, Silvia. 2016. “A Constructivist Approach for Introducing Undergraduate Students to Special Collections and Archival Research." RBM: A Journal of Rare Books, Manuscripts, and Cultural Heritage 17 (2): 148-171.

Winograd, Morley, and Michael Hais. 2014. "How Millennials Could Upend Wall Street and Corporate America.” The Brookings Institution. https://www.brookings.edu/wpcontent/uploads/2016/06/Brookings_Winogradfinal.pdf. 